\title{
Substance use prevention: evidence-based intervention
}

Maria Renstrom ${ }^{7}$, Marica Ferri ${ }^{2}$ and Ahmed Mandil ${ }^{3}$

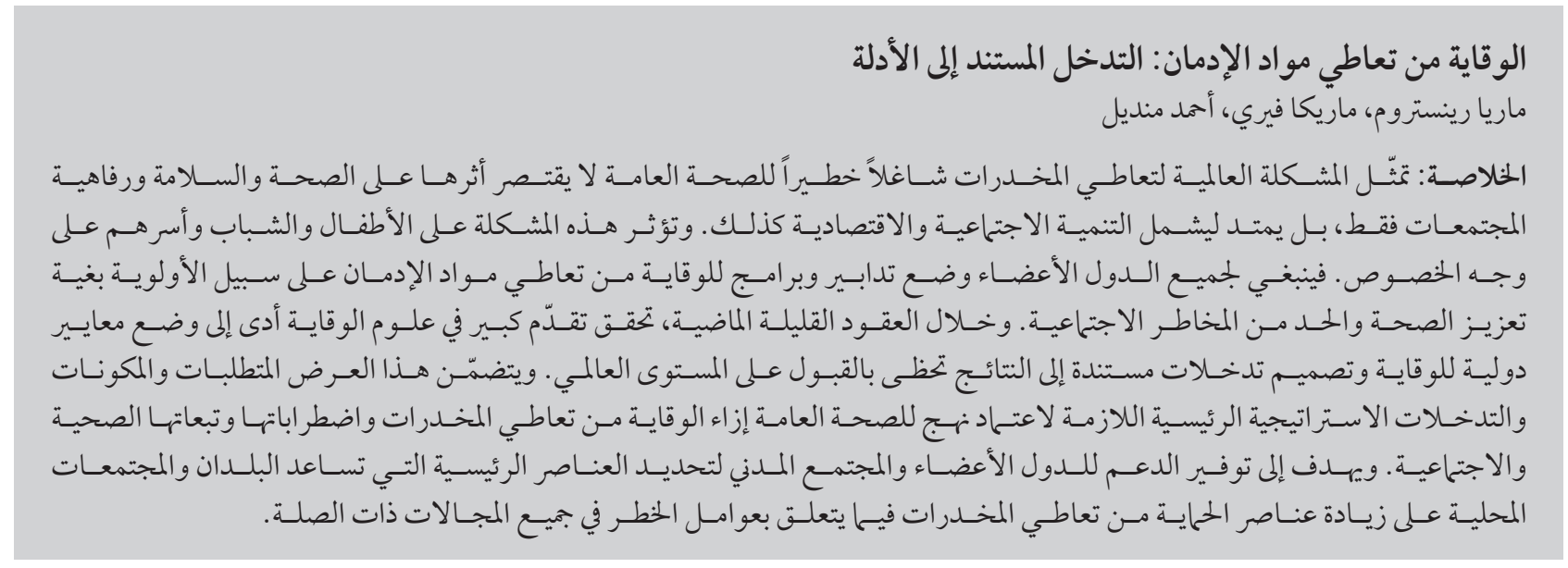

ABSTRACT The global substance use problem is a serious public health concern that affects not only health, safety and well-being of communities, but also social and economic development. It particularly affects children, young people and their families. All Member States should set substance use prevention measures and programmes as a priority in order to promote health and reduce social harm. During the past few decades there has been a significant advance in prevention science that has led to the development of international prevention standards and globally accepted evidence-based interventions. This review looks into the key requirements, components and strategic interventions needed for a public health approach to prevention of substance use and disorders, and its health and social consequences. It aims at supporting Member States and civil society to identify the key elements that support countries and local communities to increase the number of substance use protective approaches in relation to risk factors across all relevant domains.

\section{Prévention de l'utilisation de substances psychoactives : interventions reposant sur des bases factuelles}

RÉSUMÉ Le problème mondial posé par l'usage de la drogue constitue une préoccupation de santé publique sérieuse qui a non seulement des répercussions sur la santé, la sécurité et le bien-être des communautés, mais aussi sur le développement économique et social. Il affecte particulièrement les enfants, les jeunes et leurs familles. Tous les États Membres devraient accorder la priorité aux mesures et programmes de prévention de l'usage des substances psychoactives afin de promouvoir la santé et de diminuer l'impact social. Au cours des dernières décennies, on a observé une avancée notable dans le domaine des sciences de la prévention, qui a conduit à l'élaboration de normes de prévention internationales et à la mise en place d'interventions reposant sur des bases factuelles reconnues à l'échelle mondiale. La présente analyse a passé en revue les exigences, composantes et interventions stratégiques principales requises dans le cadre une approche de santé publique de prévention de l'utilisation des substances psychoactives et des troubles associés, ainsi que ses conséquences sanitaires et sociales. Elle vise à soutenir les États Membres et la société civile dans l'identification des éléments clés permettant d'aider les pays et les communautés locales à augmenter le nombre d'approches de protection contre l'utilisation de substances psychoactives en rapport avec les facteurs de risque dans tous les domaines pertinents.

${ }^{7}$ World Health Organization, Geneva, Switzerland. ${ }^{2}$ European Monitoring Centre for Drugs and Drug Addiction, Lisbon, Portugal. ${ }^{3}$ World Health Organization Regional Office for the Eastern Mediterranean, Cairo, Egypt. (Correspondence to: Marica Ferri: marica.ferri@emcdda.eu).

Received: 20/05/16; accepted 13/04/17 


\section{Introduction}

The issue of drug policy has been high on the political agenda lately. Mostly due to the special session of the United Nations (UN) General Assembly on the world drug problem (UNGASS 2016) which was convened in New York from 19 to 21 April 2016. Its purpose was to review the progress made in implementation of the Political Declaration and Plan of Action on International Cooperation towards an Integrated and Balanced Strategy to Counter the World Drug Problem. At the UNGASS, the UN member states adopted a joint commitment to effectively address and counter the world drug problem. In the commitment, the governments declare that they will take effective and practical measures that protect people and prevent progression to drug use disorders. The governments also promise increasing the availability, coverage and quality of scientific evidence-based prevention measures and tools that target relevant age and risk groups in multiple settings (1).

\section{Prevalence and health burden}

The majority of those who develop frequent and long-term substance use and substance use disorders (SUDs) later in life begin in adolescence. There are clear associations between early onset and frequent use of drugs and concurrent and subsequent poor health, violence, injuries, psychosocial, and educational outcomes (2). Substance use has a significant contribution to the global burden of disease. According to the Global Burden of Disease Study 2010, mental and substance use disorders accounted for $7.4 \%(6.2-8.6)$ of all disability-adjusted life years (DALYs) worldwide. Among DALYs caused by mental health and substance use disorders, Illicit drug use disorders accounts for $10.9 \%(8.9-13.2)$ and alcohol use disorders for 9.6\% (7.7-11.8)(3). Recent figures from the World Health Organization (WHO) reveal that drug use disorders accounted for $0.55 \%$ of the total global burden of disease (GBD) $(0.70 \%$ for men and $0.37 \%$ for women) (4).

In 2012, approximately 3.3 million net deaths (5.9\% of all global deaths) were attributable to alcohol consumption, while $5.1 \%$ of the global burden of disease and injury were attributable to alcohol consumption (5). Worldwide, approximately $34 \%$ of 15 to 19 -year-old adolescents are estimated to be current drinkers (5), while cannabis is, by far, the most frequently used illicit drug by adolescents and young adults (6). However, tobacco is the only legal drug that kills many of its users when used exactly as intended by manufacturers (7). WHO has estimated that tobacco use, whether smoking or smokeless, is currently responsible for the annual global death of 6 million people, many of whom die prematurely. This includes approximately 600000 people estimated to die from the effects of secondhand smoke (sometimes referred to as environmental tobacco smoke). Although often associated with ill-health, disability and death from chronic noncommunicable diseases, tobacco use is also associated with increased risk of death from communicable diseases (7).

Data on substance use among young people is often limited. Schoolbased surveys can provide useful comparisons within and across countries, but do not include young people who are not attending schools. Most of the public access data comes from highincome countries in Europe and North America, as well as Australia and New Zealand.

\section{Substance use prevention}

Substance use and substance use disorders are largely preventable. In fact, evidence-based substance use prevention can save both lives and money, since frequent substance use is not only associated with numerous social and health consequences for the individual drug users but also for their families, friends, work colleagues, health and social sector and economic development.

Togenerate the evidence to respond to the substance use problem, much of the research over the past decades on substance use prevention has been trying to determine which factors increases the risk of initiation of substance use/ SUDs; how this behaviour develops; and how substance use and its health and social harms can be prevented or minimized. As a result, evidence-informed prevention programmes and interventions are currently able to address the identified risk factors for substance use, and to promote protective factors found to be the most relevant to reduce substance use/SUDs. Research shows that crucial periods of risk for substance use occur during key life transitions. An important community level risk factor is access to and availability of substances and normative beliefs that substance use is "tolerated and accepted" (8).

The Sustainable Development Goals (SDGs) adopted by the UN General Assembly in September 2015 acknowledges the right of all girls and boys to have access to quality early childhood development, care and preprimary education. Additionally in SDG 3.5 it asks for strengthening the prevention and treatment of substance abuse, including narcotic drug abuse and harmful use of alcohol (9).

\section{Development and implementation of effective substance use prevention framework: key issues}

Substance use prevention is one of the key components of a public health approach. Evidence-based substance use 


\section{Box 1. Risk and protective factors $(8,10)$}

\section{Risk factors}

- High availability of substances in the environment

- Substance use/dependence among patients

- Substance use by older siblings

- Lack of parental supervision

- Low quality of family relations

- Family disruption and problematic economic conditions

- Low perception of harm in society, especially among your people

- Individual risk factors: mental disorders, conduct disorder, aggressive behaviour, academic failure

\section{Protective factors}

- Reduced availability and high prices

- Parental monitoring

- Academic competence

- Effective policies

- Strong neighbourhood attachment

- Strong positive attachment or bond between children and parents

- Positive external support system

- Individual attributes such as positive temperament and disposition, self-control

prevention has a potential for preventing, delaying or reducing substance use, and/or its negative health and social consequences, both for individuals and society. Substance use prevention activities are commonly thought of as being most relevant to young people; however, prevention is equally relevant to all age groups. Prevention strategies and programmes that are based on scientific evidence, working with whole populations, families, schools, and communities as comprehensive multisector approaches to prevention, has gained traction in recent years. The risk and protective factors are summarized in Box 1 (10).

The process and framework to develop an effective national substance use prevention programme or strategy is crucial. Firstly, a supportive policy and legal framework is a prerequisite. Secondly, to be able to make a difference, strong leadership and a solid base of awareness and political commitment are needed. Substance use prevention and health promotion should never be stand-alone interventions, but should be integrated parts of national public health and/or substance use policies, especially in low- and middle-income countries. If possible, the interventions should undergo cost-effective analysis in order to select the policy/intervention that would yield the best outcome/ result (i.e. best-buys; cost-effective interventions). Furthermore, they should be developed in coordination with multiple sectors at all levels. If developed and adopted at the national level, the prevention programme can also pave the way for designing strategies and programmes at local levels that are costeffective, evidence informed, and that address actual needs of the community, specifically the more vulnerable groups (e.g. young people and subgroups).
When resources are limited, the most cost-effective interventions that address the needs of the community should be prioritized, followed by training of required staff and allocation of adequate resources to sustain the long-term viability of programmes. In general, an effective prevention framework of action requires the following characteristics and should:

- have clear public health objectives, cover the whole prevention chain, leading from universal and selective to indicated prevention,

- address each community's specific problems - retaining the core elements of the general framework,

- be developed to meet the main targeted area/group, namely;

- the age of the target group,

- the level of risk of the target group and, 
- the setting in which the intervention/strategy is planned to be delivered.

- be based on scientific evidence with involvement of relevant stakeholders in the whole process of development and implementation,

- include screening, brief intervention, and referral to treatment to identify, reduce, and prevent substance use disorders,

- target the most important risk and protective factors at individual, environmental and societal levels,

- be implemented in multiple settings (e.g. educational settings, workplace, media) for longer periods of time with subsequent follow-up sessions,

- aim at working with schools, families, and communities to ensure that children and youth - especially the most marginalized and poor - grow and stay healthy and safe into adulthood.

Depending on these factors interventions can be, a) environmental, addressing societies or social environments and targets social norms including market regulations; b) universal, targeting whole populations; c) selective, targeting subsets of population; and d) indicated, targeting individuals with identified risk. Indicated prevention addresses intrapersonal factors, while selective prevention addresses social vulnerability (10). The most challenging part for all policies and interventions is to successfully implement them and manage to engage the community and the stakeholders in the process. There are some steps to be taken, namely:

- starting with assessing the prevention needs based on, for example, epidemiological data, focus groups or mapping (needs assessment),

- building prevention capacity and identifying if and how the aims of the intervention can be achieved with available resources (resource assessment),

- developing a strategic plan,
- selecting effective and science-based family, school and community-based prevention programmes, policies and practices,

- starting the process and outcome evaluation at the beginning of the intervention to enable the evaluation of both outcomes, the process of delivering the intervention and the implementation of the programme and,

- feedback to the actors/policy makers to retain their commitment and safeguard a long-term engagement.

In summary, the focus of substance prevention should be on a comprehensive and coherent package of interventions based on the evolving evidence for prevention, which can decrease health problems and health-compromising behaviours, improved educational and work outcomes, and contribute to positive health. The package should include age and culturally relevant interventions targeting individuals, families and vulnerable youth and incorporate screening and briefinterventions, motivational interviewing, family management programmes, interactive social/life skills programmes and monitoring etc. The interventions should target different life stages, different settings such as health services, school settings and recreation etc., and involving all relevant stakeholders for its implementation, observing the full range of human rights.

\section{Substance Use Prevention in primary health care settings:}

The Alcohol, Smoking and Substance Involvement Screening Test (ASSIST) was developed under WHO's auspices in response to the overwhelming global public health burden associated with psychoactive substance. The ASSIST was designed to be used in primary health care (PHC) settings, where hazardous and harmful substance use among visitors may go undetected, or even become worse. The package includes an 8-item questionnaire designed to be administered by a PHC worker to a visitor, which takes 5-10 minutes to administer. It was designed to be used for screening for the following substances, tobacco products; alcohol; cannabis; cocaine; amphetamine-type stimulants (ATS); sedatives and sleeping pills (benzodiazepines); hallucinogens; inhalants; opioids, as well as other drugs. The ASSIST determines a risk score for each substance, which is used to start a discussion with PHC visitors about their substance use. Such score falls into a 'lower, 'moderate' or 'high' risk category which determines the most appropriate intervention for that level of use (i.e. 'no treatment', 'brief intervention' or 'referral to specialist assessment and treatment' respectively). Scores in the midrange on the ASSIST are likely to indicate hazardous or harmful substance use ('moderate risk'), while higher scores are likely to indicate substance dependence ('high risk'). The ASSIST obtains information from PHC visitors about lifetime use of substances and use of substances and associated problems over the last 3 months. Taken together, these questions provide an indication of the level of risk associated with the PHC visitor's substance use, and whether use is hazardous and likely to be causing harm (now or in the future) if use continues (11).

\section{Prevention interventions during life course - what works?}

\section{Prenatal \& Infancy}

Universal: Screening and brief Intervention targeting all pregnant women could be introduced as a preventive intervention in maternity care as a part of ordinary care (12). Screening and brief interventions, which can be delivered by nurses or midwives who work 
in PHC, hospital settings or antenatal care, are among the most effective and cost-effective prevention services (13).

Selective: Targeting women at high risk and conducted by trained nurses or social workers. Pregnancy and motherhood are periods when women are receptive to address their use of substances that would harm the fetus. It is also the period when pregnant women would address their own dependence. Evidence-based Referral to Treatment (SBIRT) is an evidence-based practice used to identify, reduce and prevent high-risk use and dependence on alcohol and illicit drugs (14). There are some positive outcomes from prenatal and infancy visits for low-income unmarried women with substance use disorders, with a focus on improving the health of both the mother and her baby. The available evidence indicates that this intervention should be delivered by trained health workers through regular visits over two years of the baby's life. The health worker should provide basic parental training and support the mothers to address both health and socio-economic needs (15).

Indicated: Targeting women with substance use disorders, offering treatment that follows rigorous clinical guidelines based on scientific evidence (12).

\section{Children and adolescents}

Parenting skills programmes: Prevention programmes and interventions are most effective during key transition periods, for example the period of transition from middle to high school. Even if the target group of the intervention is children in early or middle childhood the most cost-effective intervention is universal in addition to selective parenting skills programmes $(16,17)$. In well-resourced countries, universal programmes can be offered to all parents, but in low- and middle-income countries these interventions could be selective or indicated to be more cost-effective alternatives.
Universal: In middle childhood, the role of schools and peer groups grow in importance and there are several good reviews that have found certain interactive school-based programmes that can prevent substance use. $(17,18,19)$. Universal programmes targeting and implemented during early adolescence have more positive results in preventing substance use than programmes targeting younger or older children. To be effective, the interventions/programmes should use interactive methods delivered through a series of structured sessions once a week and over several years by trained facilitators. This can be a costly intervention if implemented correctly with several booster sessions and education of educators.

Selective: Evidence exists that early education in support of social and cognitive development of pre-school children ( $2-5$ years old) from deprived communities can reduce cannabis use as well as other illicit drugs and tobacco smoking. The intervention should be delivered by trained teachers and the sessions should be daily (20). Most importantly, it has now been shown that disseminating information alone, using ex-drug users and focusing only on the building of self-esteem and emotional unstructured sessions, have no observed prevention outcomes (8).

\section{Targeting families}

There is a dearth of methodologically sound research in this area, but the research that has been conducted does suggest strongly that the family can have a central role in preventing substance use and later misuse among young people. Universal and selective prevention interventions delivered to families are shown to be able to deter, or at least delay, the onset of substance use by children and adolescents. To be effective, the intervention should involve the whole family in the prevention activities. It should include parental functioning and/or parent-children relationships, and provide family members with the information and skills indicated to be necessary to prevent substance use. Universal prevention programmes to families can be delivered to family-as-asystem without any prior screening for vulnerability.

Selective: In prevention, a prior family screening would improve effectiveness when targeting families at risk of substance-related problems. Families at risk are those where one or more family members have substance use problems/SUDs, and/or families with high levels of parental conflict and violence, poor quality of relations, family disruption and/or serious economic problems. Indicated prevention to highrisk families requires close collaboration between parents, teachers, health and/ or social services and home visits for disadvantage families (16).

\section{Prevention \\ interventions targeting different settings (education sector/ communities/ general population)}

\section{Education sector response}

The education sector can play a key role in preventing and reducing substance use among children and young people not only because this will be effective in improving health outcomes, but it would also improve learning and school performance. A summary of evidence-based preventive approaches is presented in Box 2. Ensuring that schools deliver effective programmes to reduce substance use requires action at different levels including

- National and school level policy framework to prevent and address substance use among children and young people;

- National curricula (contents and methods for the delivery of these con- 
tents) including skills-based prevention education;

- Evidence-based interventions related to curricula implemented in educational institutions;

- Evidence-based interventions related to the school environment implemented in educational institutions;

- School health services, providing both prevention and care and support for young people who use substances;

- Training and support for teachers, school health practitioners and other school staff to plan, develop and implement a comprehensive schoolbased intervention strategy;

- Management, coordination, and evaluation of response in the education sector including monitoring of prevalence of substance use among children and young people.

Schools: A systematic examination of reviews of school-based substance use prevention was conducted as a part of the preparations for the UNESCO, UNODC and WHO international expert meeting held in Istanbul, Turkey, from 29 September to 2 October, 2015. The text below is just a short summary of the review and more information can be found in the UNESCO booklet, Education Sector Responses to Substance Use among Children and Young People (21).

Since adolescence often is per se a risk factor, and the majority of substance users start to use at this age, school is an efficient setting for universal prevention. Schools can offer a systematic and efficient way of reaching large numbers of young people by providing all individuals with the information and skills necessary to help them prevent problems and prepare them for the adult life. The school itself can become an important protective factor. Evidence suggests that school-based programmes to prevent substance use can have positive impacts on improving school attainment and engagement as well as health and wellbeing in general. In addition, policies aimed at keeping children in school can play an important role. Nevertheless, since school-based programmes on substance use often only reach a low percentage of all school children, they should be scaled up and form part of more comprehensive strategies for drug use prevention in order to achieve a wider population-level impact. Furthermore, education-sector responses to substance use depend on providing sufficient training for teachers, school health practitioners and other school staff to effectively deliver interventions. Thus, training is recognized as a critical component of prevention implementation.

The different types of school-based preventive interventions that are shown to impact on different types of substance use or harm include the following:
Universal: Multicomponent interventions delivered at school and based on social influence and/or learning social skills are helpful for reducing substance use, especially cannabis.

Selective: Interactive interventions targeted at problem students are proven to help reduce substance use and 'drink-driving' behaviour. Peer-led interventions are shown to reduce substance use and tobacco use.

Indicated: School settings working together with the school health systems can also be an efficient setting for indicated prevention when organised in a non-stigmatising way.

Programmes based on a combination of social competence and social influence approaches seemed to have better results than programmes only based on social competence or social influence approaches alone, with positive results in preventing marijuana use at longer follow-up, and in preventing any substance use.

\section{EU-DAP (Unplugged) Experience:}

The effect of a school-based substance abuse prevention program, called Unplugged, was evaluated within the "European Drug Addiction Prevention (EU-DAP) Trial" in several European countries, concentrating on frequency of alcohol consumption and alcoholrelated problem behaviours, in addition to tobacco and cannabis use among

\section{Box 2. Evidence-based prevention approaches relevant to school settings (8).}

\section{Evidence-based prevention approaches relevant to school settings as defined in UNODC international standards, including the following:}

- Policies to keep children in school

- Classroom environment improvement programmes

- Personal and social skills education

- Prevention education based on personal and social skills and social influence

- School policies and culture

- Addressing individual psychological vulnerabilities

- Brief intervention (mentoring, parenting skills programmes, and other community based prevention interventions) 
European students, more than 10 years ago. Thus, during 2004-2005, a total of 7079 students aged $12-14$ years from 143 schools in 7 European countries participated in this cluster randomized controlled trial. Schools were randomly assigned to either control (65 schools, 3532 students) or to a 12 -session standardized programme based on the comprehensive social influence model (78 schools, 3547 students). Alcohol use and frequency of alcohol-related problem behaviours were investigated through a self-completed anonymous questionnaireat baseline and 18 months thereafter. The association between intervention and changes in alcoholrelated outcomes was expressed as odds ratio (OR), estimated by multilevel regression model. This intervention prevention programme was found to be associated with a decreased risk of reporting alcohol-related problems (OR $=0.78,95 \%$ confidence intervals $[\mathrm{CI}]$ $=0.63-0.98)$. The risk for alcohol consumption was not modified by exposure to the program $(\mathrm{OR}=0.93,95 \% \mathrm{CI}=$ 0.79-1.09). In the intervention group, non-drinkers and occasional drinkers at baseline were found to progress towards frequent drinking less often than in the control group. Thus, school curricula based on the comprehensive social-influence model can delay progression to frequent drinking and reduce occurrence of alcohol-related behavioural problems, as demonstrated among European students (22).

Such EU-DAP methodology and applications were extended to several Eastern Mediterranean Region (EMR) member states / institutions, including: Egypt (General Secretariat of Mental Health; Cairo University); Jordan (Anti-narcotic Directorate and National AIDS Program, Ministry of Health); Kuwait (Ministry of Education); Lebanon (NGOs as: Mentor Arabia, SKOUN, OUM El-Nour); Morocco (NASSIM NGO); and United Arab Emirates (National Rehabilitation
Center). Results of implementation are under evaluation (19).

\section{Communities}

Community interventions can address the whole community; however they do not necessarily need to address all members of the community. The community-wide approach focuses on engaging an entire community, rather than focusing on implementing only one particular programme. It allows a community to lead, plan, implement and evaluate its efforts across community sectors in relevant settings for individuals, families, schools, workplaces and the community at large. This approach is shown to work both in low, middle and high-income countries.

Universal: Engaging community support groups and involving family members, are shown to help young people living in problem families.

Selective: Multicomponent and interactive interventions delivered in the community are shown to reduce drug, tobacco and alcohol use in high-risk youths. Multicomponent interventions involving the community have also been shown to reduce car accidents, public nuisance and crime related to alcohol consumption

Selective: Mentoring programmes are shown to reduce alcohol use in young people.

Selective: Targeting clubs and party settings can address potential harmful use of alcohol and drug use in recreational settings, both at national and international level. Using several tools such as brochures, and community mobilisation supported by media campaigns.

Selective: Engaging police supervision in venues and their immediate surroundings is shown to reduce public disorder while training staff on preventing / reducing clients' alcohol consumption and intoxication levels (16).

\section{The general population/ universal}

One of the most effective policies to prevent substance use/SUDs is restrictions on the availability of substances by adopting and implementing an effective and balanced substance control policy including both supply and demand reduction. Interventions targeting the general population could be through taxation, enforced age limits, restrictions on advertising (legal substances), or reducing illicit production, trafficking and sales of illicit drugs. Mass-media campaigns associated with other interventions, both school-based and/or community-based, can help reduce car accidents and drug-driving behaviours. Drink and drug driving policies and countermeasures have been shown to be effective both in reducing the number of road crashes, mortality and morbidity but also to reduce substance use.

\section{Monitoring and evaluation}

Fewer than half of all countries monitor child and adolescent alcohol use, with even fewer monitoring drug use. A lack of national monitoring reduces the possibility of making informed prioritization and measuring the outcomes/impacts of different policies, programmes and interventions.

\section{Conclusion}

Substance use prevention is one of the key components of a public health approach. Evidence-based substance use prevention has a potential for preventing, delaying or reducing substance use, and/or its negative health and social consequences, both for individuals and societies.

As several of the behavioural risk and protective factors - especially during childhood and early school years - are found to be relevant to both substance use, mental health and violence prevention, a comprehensive approach to the above mentioned risk behaviours 
when targeting children and families could be cost-effective, likewise for monitoring these outcomes in a more coherent way in the future. In addition, a particular focus is needed on the role of the health sector. Health systems need to scale up their contributions to prevent substance use/SUDs. The health sector, especially primary health care and the school health services, has a pivotal potential for early identification and counselling and enhanced an contribution to counter the world drug problem.

WHO policy briefs, WHO mhGap, the European Monitoring Centre for Drugs and Drug Addiction (EMCDDA) Best Practice Portal and the United Nations Office on Drugs and Crime
(UNODC) International Standards on Drug Use Prevention can be used, among others, as planning tools to facilitate the development and coordination of preventive work and engage national and local actors and sectors in the global drug policy dialogue.

Funding: None.

Competing interests: None declared.

\section{References}

1. Transnational Institute (TNI). The UNGASS outcome document: diplomacy or denialism? Amsterdam: TNI; 14 March 2016 (https://www.tni.org/en/article/the-ungass-outcomedocument-diplomacy-or- denialism, accessed 12 April 2017).

2. Burkhart G, Simon R. Prevention strategies and basics. In: el-Guebaly N, Carrà G, Galanter M, editors. Textbook of addiction treatment: international perspectives, Milan: Springer; 2015:115-142.

3. Whiteford HA, Degenhardt L, Rehm J, Baxter AJ, Ferrari AJ, Erskine $\mathrm{HE}$, et al. Global burden of disease attributable to mental and substance use disorders: findings from the Global Burden of Disease Study 2010. Lancet 2013; 9:382 (9904):1575-86.

4. World Health Organization. Health statistics and information systems. Estimates for 2000-2015. Geneva: World Health Organization; 2016 (http://www.who.int/healthinfo/global_burden_disease/estimates/en/index2.html, accessed 12 April 2017).

5. World Health Organization. Global status report on alcohol and health. Geneva: World Health Organization; 2014 (http://apps. who.int/iris/bitstream/10665/112736/1/9789240692763_ eng.pdf, accessed 12 April 2017).

6. United Nations Office on Drugs and Crime (UNODC). World drug report. Vienna: UNODC; 2015 (https://www.unodc. org/documents/wdr2015/World_Drug_Report_2015.pdf, accessed 12 April 2017).

7. World Health Organization. Global report on trends in prevalence of tobacco smoking. Geneva: World Health Organization; 2015 (http://apps.who.int/iris/bitstre am/10665/156262/1/9789241564922_eng.pdf, accessed 12 April 2017).

8. United Nations Office on Drugs and Crime (UNODC). International standards on drug use prevention. Vienna: UNODC; 2013 (https://www.unodc.org/documents/prevention/ UNODC_2013_2015_international_standards_on_drug_use_ prevention_E.pdf, accessed 12 April 2017).

9. Open Working Group proposal for Sustainable Development Goals. http://undocs.org/A/68/970

10. European Monitoring Centre for Drugs and Drug Addiction (EMCDDA). Best Practice Portal. Lisbon: EMCDDA; 2016 (http://www.emcdda.europa.eu/best-practice, accessed 12 April 2017).

11. Humeniuk R, Henry-Edwards S, Ali R, Poznyak V, Monteiro M. The alcohol, smoking and substance involvement screening test (ASSIST): manual for use in primary care. Geneva: World Health Organization; 2010 (http://apps.who.int/iris/bitstre am/10665/44320/1/9789241599382_eng.pdf, accessed 12 April 2017).

12. World Health Organization. Guidelines for the identification and management of substance use and substance use disorders in pregnancy. Geneva: World Health
Organization; 2014 (http://apps.who.int/iris/bitstre am/10665/107130/1/9789241548731_eng.pdf, accessed 12 April 2017).

13. Solberg LI, Maciosek MV, Edwards NM. Primary care intervention to reduce alcohol misuse. Ranking its health impact and cost effectiveness. Am J Prev Med. 2008;34(2):143-152.

14. Bernstein E, Bernstein J, Feldman J, Fernandez W, Hagan M, Mitchell P, et al. An evidence based alcohol screening, brief intervention and referral to treatment (SBIRT) curriculum for emergency department (ED) providers improves skills and utilization. Subst Abus. 2007;28(4):79-92

15. Toumbourou JW, Stockwell T, Neighbors C, Marlatt GA, Sturge $\mathrm{J}$, Rehm J. Interventions to reduce harm associated with adolescent substance use. Lancet. 2007;369(9570):1391-401.

16. United Nations Office on Drugs and Crime (UNODC). Compilation of evidence-based family skills training programmes. Vienna: UNODC; 2012 (http://www.unodc.org/docs/youthnet/Compilation/10-50018_Ebook.pdf, accessed 12 April 2017).

17. Bühler A and Thrul J. Prevention of addictive behaviours. Luxembourg: EMCDDA; 2015 (http://www.emcdda.europa. eu/attachements.cfm/att_242416_EN_TDXD15018ENN.pdf, accessed 12 April 2017).

18. World Health Organization. European framework for quality standards in school health services and competences for school health professionals. Copenhagen: WHO Regional Office for Europe; 2014 (http://www.euro.who.int/_data/ assets/pdf_file/0003/246981/European-framework-for-quality-standards-in-school-health-services-and-competencesfor-school-health-professionals.pdf?ua=1, accessed 12 April 2017).

19. European Drug Addiction Prevention Trial (EU-DAP) (http:// www.eudap.net/Contacts.aspx, accessed 12 April, 2017)

20. Substance Abuse and Mental Health Services Administration (SAMHSA). Prevention programs that address youth marijuana use. Using prevention research to guide prevention practice. Washington, DC: SAMHSA; 2014 (https://www.samhsa.gov/ capt/sites/default/files/resources/prevention-youth-marijuana-use.pdf accessed on 12 April, 2017).

21. United Nations Educational, Scientific and Cultural Organization (UNESCO), United Nations Office on Drugs and Crime (UNODC), World Health Organization (WHO). Education sector responses to the use of alcohol, tobacco and drugs. Paris: UNESCO; 2017 (http://unesdoc.unesco.org/ images/0024/002475/247509e.pdf, accessed 12 April 2017).

22. Caria MP, Faggiano F, Bellocco R, Galanti MR; EU-Dap Study Group Collaborators. Effects of a school based prevention program on European adolescents' patterns of alcohol use. J Adolesc Health. 2011;48(2):182-188. 